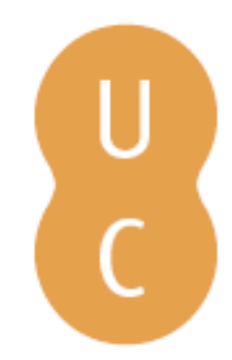

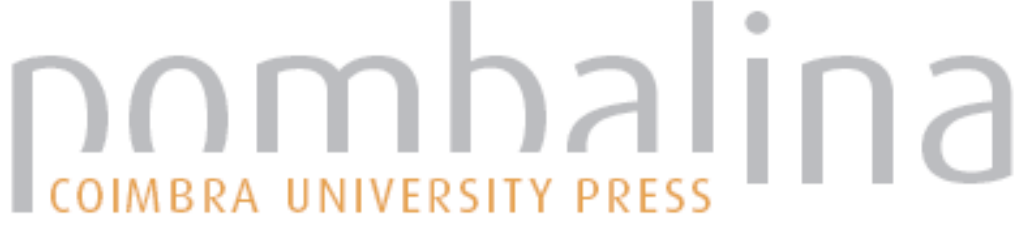

\section{Aspectos sanitarios de la ciudad de México a principios del siglo XVII}

Autor(es): López Pérez, Miguel

Publicado por: Imprensa da Universidade de Coimbra

URL

persistente: URI:http://hdl.handle.net/10316.2/32371

DOI: $\quad$ DOI:http://dx.doi.org/10.14195/978-989-26-0469-5_4

Accessed : $\quad$ 26-Apr-2023 15:17:35

A navegação consulta e descarregamento dos títulos inseridos nas Bibliotecas Digitais UC Digitalis, UC Pombalina e UC Impactum, pressupõem a aceitação plena e sem reservas dos Termos e Condições de Uso destas Bibliotecas Digitais, disponíveis em https://digitalis.uc.pt/pt-pt/termos.

Conforme exposto nos referidos Termos e Condições de Uso, o descarregamento de títulos de acesso restrito requer uma licença válida de autorização devendo o utilizador aceder ao(s) documento(s) a partir de um endereço de IP da instituição detentora da supramencionada licença.

Ao utilizador é apenas permitido o descarregamento para uso pessoal, pelo que o emprego do(s) título(s) descarregado(s) para outro fim, designadamente comercial, carece de autorização do respetivo autor ou editor da obra.

Na medida em que todas as obras da UC Digitalis se encontram protegidas pelo Código do Direito de Autor e Direitos Conexos e demais legislação aplicável, toda a cópia, parcial ou total, deste documento, nos casos em que é legalmente admitida, deverá conter ou fazer-se acompanhar por este aviso.

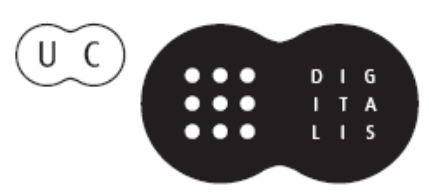


Ana Leunar Pereira João Rui Pita

[ Coordenaçä̃ ]
Rotas da Natureza

Cientistas

Viagens

Expedifgũes

Instituip̧ües

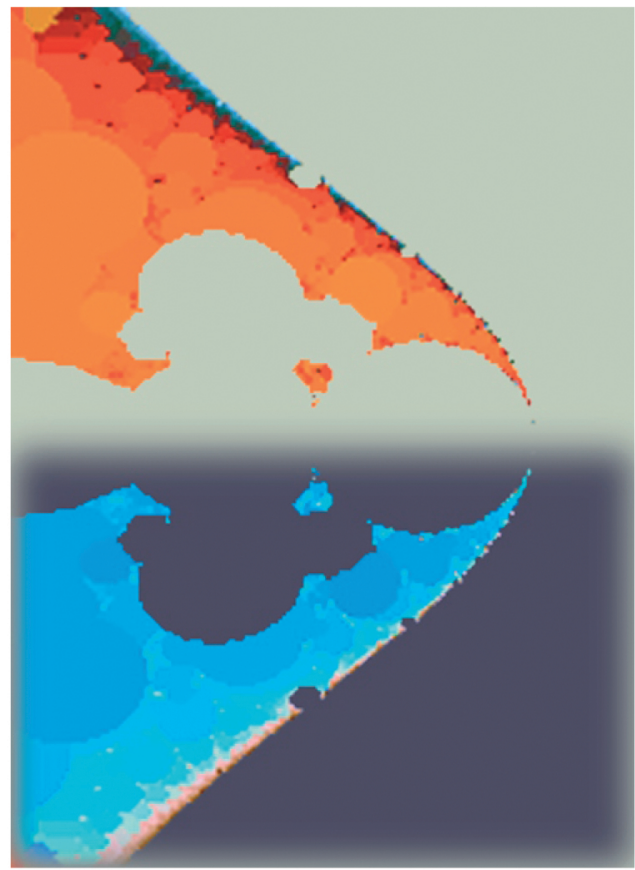




\section{Coordenaçáo Científica da Colecção Ciências e Culturas}

João Rui Pita e Ana Leonor Pereira

Os originais enviados são sujeitos a apreciação científica por referees

\section{Coordenação Editorial}

Maria João Padez Ferreira de Castro

\section{Edição}

Imprensa da Universidade de Coimbra

Email:impresauc@ci.uc.pt

URL: http://www.imp.uc.pt • Normas de publicação de colecçôes

\section{Design}

António Barros

Pré-Impressáo

António Resende

Imprensa da Universidade de Coimbra

\section{Capa}

António Barros, com imagem de E. M. de Melo e Castro, 2003 [Fractal original gerado no Fractint com tratamento no Photoshop 7.0]; Cortesia: António Barros

Impressão e Acabamento

SerSilito • Maia

\section{ISBN}

978-989-8074-12-6

\section{Depósito Legal}

Obra publicada com a colaboraçáo de:
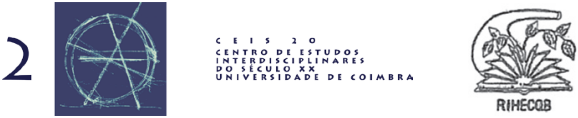

Obra publicada com o apoio de:

FCT Fundação para a Ciência e a Tecnologia

MINISTÉRIO DA CIÊNCIA, TECNOLOGIA E ENSINO SUPERTOR Portug

Programa Operacional Ciência, Tecnologia, Inovação do Quadro Comunitário de Apoio III
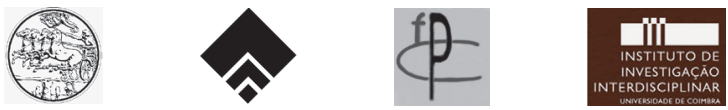

\section{Baxter}

(c) 2006, Imprensa da Universidade de Coimbra 
João Rui Pita

Ana Leonar Pereira

(Courdenação)

Rotas da Natureza

Cientistas

Viagens

Expediçũes

Instituiç̃̃es

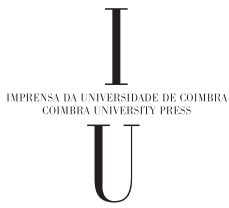

- colmbra 2006 
(Página deixada propositadamente em branco) 


\section{Aspectos Sanitarios de la CiUdad de MÉXico A PRINCIPIOS DEL SIGLO XVII}

La presencia de médicos en los virreinatos durante los siglos XVI y XVII es una cuestión bastante conocida y estudiada. Sin embargo, más allá de los rasgos generales que suelen presentarse, hay unas cuestiones anexas a dicha presencia que resultan muy llamativas para el historiador.

A principios del siglo XVII existía una nueva cultura en torno a la figura del médico, al ejercicio de su profesión y a la adecuación de la práctica médica a unos escenarios y a unos pacientes que no siempre respondían al tratamiento de la enfermedad de la misma manera que en la península. Por ello se hacían imprescindibles, dentro de esta cultura de la salud, más extensa que la de la propia formación del médico, la existencia de textos que ofrecieran información sobre muy diversos aspectos de la cotidianeidad a la que habría de enfrentarse el posible enfermo. Uno de estos aspectos era la necesidad de destacar las características climáticas y sanitarias de los núcleos urbanos.

El mejor ejemplo de todo esto lo tenemos en la figura del médico madrileño Diego de Cisneros, llegado de la Universidad de Alcalá a la Real Universidad de México. En el año 1618 publicó su «Sitio, naturaleza y propiedades de la Ciudad de México» ${ }^{1}$, donde explica cuestiones climatológicas, hidrológicas y de otros tipos con el fin de informar acerca de los elementos que tiene que considerar tanto el médico como las demás personas, con el fin de mantener la salud.

Y todo ello basado en una experiencia propia o ajena, la mayor parte, de carácter preventivo y, porqué no decirlo, de pronóstico astrológico. Tal era la finalidad de todas las informaciones que contamos sobre este periodo. En general, este tipo de testimonios y advertencias son de carácter positivo hacia el lugar descrito y nacen por la necesidad de compensar y equilibrar otro tipo de datos que, estos sí, son negativos. Veamos algunos de ellos.

El ejercicio de la medicina y la farmacia no estuvo plenamente estructurado y su funcionamiento tampoco era todo lo bueno que se podía desear. El 30 de marzo de

\footnotetext{
${ }^{1}$ Somolinos D’Ardois, German, Los impresos médicos mexicanos (1953-1618), in: Fresquet, J. L. y López Piñero, J. M. (eds), El mestizaje cultural y la medicina novohispana del siglo XVI, Valencia, 1995, p. $145-296$.
} 
1587 el Conde de Monterrey, que entonces era el Virrey de Nuevo México, escribió a Felipe II. Se quejaba de que la multitud de médicos en esa ciudad era muy grande y quería remediar "el poco crédito de ellos y opinión de que esta arte no se sabe con fundamento en esta tierra, ni se platica con la seguridad que conviene siendo tan peligroso como se deja entender ${ }^{2}$.

No le faltaba razón al Virrey. Se pedían recetas al otro lado del Atlántico desde todos los lugares y durante todo el siglo XVII ${ }^{3}$, ejercían boticarios sin licencia ${ }^{4}$ y las medicinas que había estaban en tan mal estado5, que el Rey se vio obligado a ordenar que se tiraran en alguna ocasión ${ }^{6}$. Además de la escasez de medicinas, los lugares donde administrarlas tampoco abundaban ni eran suficientes. Como ocurrió en el hospital de Nuestra Señora de la Concepción de la Isla la Española en 1557, desbordado ante la cantidad de pobres que acudían a él "por no haber otros ospitales poblados ni probeydos de lo necesario"7.

Pero no eran estos todos los problemas. Hay bastantes noticias de la no adaptación a las colonias y de la preferencia de curarse en España. Por ejemplo, en 1538 varios médicos de la isla de Santo Domingo determinaron que la mujer de un tal Melchor de Torres sólo podía curarse de cierta enfermedad contagiosa volviendo a Sevilla ${ }^{8}$. Debido al clima pidieron volver a la península desde Quito el oidor Matías de Peralta9, el canónigo Diego Ortiz de Velasco ${ }^{10}$, Francisco de Cáceres, contador, o el tesorero Gaspar Alonso de Zúniga ${ }^{11}$.

Las epidemias se sucedían en México, como la que hubo en 1577 por todo el territorio $^{12}$, o la que hubo en 1595 , «entre los españoles y mestiços mulatos y negros

${ }^{2}$ AGI (Archivo General de Indias), México; 24, no 8, 3v-; 1587-03-30.

${ }^{3}$ Carta de Francisco Fernández de Madrigal a los jueces oficiales de la Casa de Contratación para que sin más dilación envíen las recetas que le ha pedido Bernardino de Valdés de las partidas entregadas al poderhabiente del tesorero general del Consejo. AGI, Quito; 209, L.3 38R-39R; 14 de julio de 1651.

${ }^{4}$ Cédula Real a la Audiencia de la Isla Española: que Andrés de Acevedo, boticario, estante en esa tierra ha hecho relación que él no está examinado en dicho oficio y porque no puede venir a examinarse a estos reinos, suplica se haga que le examinen ahí un doctor en medicina y un boticario y hallandole hábil le den título de ello. AGI, Santo Domingo; 899, L.1, F.229; 31 de agosto de 1561.

5 «El Doctor Bartolomé de Figueroa, médico, ha hecho relación que va con su mujer y casa a vivir y permanecer en esa tierra y porque los boticarios que en esta residen tienen las medicinas muy añejas y simples y ello es causa de grandes estragos y daños en los enfermos». AGI, Panamá; 235, L. 7, 16v-17r; 6 de septiembre de 1538 .

${ }^{6}$ Cédula Real a los oidores de la audiencia de Tierra Firme para que cuando les parezca hagan visitar las boticas que haya en esa tierra y provean y se tiren las medicinas y cosas que se hallaren en mal estado para que no puedan venderse, pues SM ha sido informada q pasan boticarios con las medicina preparadas desde estos reinos, q en cuanto llegan a aquella tierra se corrompen. AGI, Panamá; 235, L. 6. 195v-196r; 16 de abril de 1538 .

${ }^{7}$ AGI, Santo Domingo; 899, L.1, F.24v; 24 de junio de 1556.

${ }^{8}$ AGI, Santo Domingo; 868, L.1, 153v; 20 de diciembre de 1538.

${ }^{9}$ AGI, Quito; 28, no 43; 28 de marzo de 1612.

${ }^{10}$ AGI, Quito; 80, no 37; 15 de abril de 1611.

${ }^{11}$ AGI, Quito; 8. r.24, n.76; 10 de enero de 1590.

${ }^{12}$ AGI, México, 20, nº 1. 
libres y esclavos, provocando que la gente estuviera afligida y atemorizada» ${ }^{13}$, o la del año $1693^{14}$.

Es en esta relación de elementos negativos donde debemos buscar la razón de la existencia del texto de Cisneros. En este sentido, la historia del ámbito médico y farmacéutico en la Nueva España es más que la mera descripción de formas de ejercer la medicina, ya que las prácticas médicas involucran tanto al ser humano como a la naturaleza y así, a partir de su estudio, es posible inferir la concepción de mundo que se tenía, la conceptualización de la naturaleza y su funcionamiento.

Se ha elegido el estudio de la ciudad de México porque si bien fue una ciudad de renombre, al no haber tenido una ubicación geográfica que le permitiera un contacto permanente, rápido y efectivo por estar ubicada en un lugar de difícil acceso además de su evidente distancia de los puertos marítimos, puede considerase que se encontraba aislada. Este aislamiento geográfico despierta la curiosidad sobre cómo se consolidaron allí las prácticas médicas. México en sí misma es un conjunto complejo para ser delimitado ya que la ciudad no tenía unos confines específicos y su influencia y cercanía con otros núcleos poblacionales hace que sea difícil establecer una delimitación clara, concisa y verdadera.

Todas estas cosas son las que refleja nuestro autor. Tal y como el doctor Cisneros nos dijo, su texto lo escribió "para el ejercicio de la medicina, su incertidumbre y dificultad sin el de la Astrología». Su objetivo y el planteamiento del autor para describirlo no es más que el resultado del deseo de ser útil. Útil a los que lleguen, para evitar el desconcierto. La autoridad que le permite realizar este ejercicio tiene varias fuentes. La primera la experiencia propia. Pero hasta ésta ha de ser autorizada. Y esto lo solventa de la forma más rotunda. Por un lado el aval de su formación en la Universidad de Alcalá. El ser español era un elemento fundamental para la vida práctica ya que determinaba la posición jerárquica dentro de la sociedad, así como las posibilidades de acceder a ciertos oficios.

En el nivel de la medicina resultaba indispensable demostrar que se había pasado por el aprendizaje en Europa, ya que esta era la única manera consensuada y aceptada de legitimar el conocimiento. Sus argumentos son contundentes: él considera que no solamente debe ser permitido que se ejerza en el Nuevo Reino la medicina aún cuando no se tengan títulos, sino que cree que lo importante es que el practicante haya vivido lo suficiente en América para haberse naturalizado y así pueda comprender las características de las enfermedades y las curas en estas latitudes. Sin duda, la forma como se ejerció la medicina en el Nuevo Mundo tenía características que la diferenciaban de la clásica, no solamente por las distintas enfermedades contra las que se enfrentaron sino también por las particularidades del comportamiento de los cuerpos humanos en otras latitudes.

Refiriéndose a Galeno, el influjo de la naturaleza, el intercambio de humores entre el entorno y el individuo, generan una necesidad terapéutica específica. Para él, ni el mismo médico del Rey de España y todo su imperio ultramarino, podría venir a América y tener éxito inmediato con sus intentos de curar pues sería abrumado por

\footnotetext{
${ }^{13}$ AGI, México, 23, no 86.

${ }^{14}$ AGI, Mexico, 60, R.5, no 22.
} 
aquello que no podía haber aprendido con sus libros y sus maestros sencillamente porque era algo que, desde el conjunto de conocimiento españoles, hasta ahora, por la práctica y observación, se estaba conociendo. Cuando cree haber demostrado sus cualidades, su conocimiento de la tradición clásica y la experiencia en América, lo cual hace de él el candidato idóneo para hablar de estas tierras.

Estamos ante la descripción global de una ciudad, de sus propiedades geográficas y de la incidencia de éstas en la salud sus habitantes. Más aún, los clasifica estableciendo una tipología según su experiencia. Cisneros echa mano de todo el andamiaje teórico de la medicina de aquéllos tiempos, teniendo como puntal básico la concepción de la salud como el equilibrio entre los cuatro humores. Pero que apelase al galenismo y el hecho de contrastarlo con sus experiencias propias no es más que la introducción de un sutil carácter innovador de Cisneros. El galenismo también contenía un profundo valor psicológico que es contrapuesto a la falta de fundamento y a la eficacia curativa. La ciencia médica de Cisneros es y se va realizando a base de todo un depósito de observaciones seguida de un ejercicio de observación y análisis.

Otro componente en las palabras de Cisneros es la dieta. La dieta es la principal fuente de salud y la garantía de una larga vida. Así nos dijo que :

"Hay otra causa muy poderosa en esta ciudad [...] que es el exceso y desorden con que se da de comer a los enfermos, $y$ desto hay mucho en todas partes, mas en Mexico yrremediable, porque a todas horas y tiempos están dando de comer, ya pistos, atoles, aguas distiladas de substancis y otras cosas con las cuales agravan la enfermedad.»15

Otros elementos que conforman el grupo de informaciones son si los habitantes de la ciudad de México son nacidos en España o no, la influencia de sus diferentes complexiones ate la enfermedad, qué tipo de mal y con qué intensidad afecta a unos y a otros. Además, y he aquí la importancia del texto de Cisneros, introduce como novedades los diferentes tipos de vientos que afectan a la ciudad y las particularidades de las aguas y su naturaleza. Además incluye las características propias de las estaciones anuales, como su duración, intensidad, amplitud térmica de cada una, etc. esto hace que el médico haya de valerse, como ya se ha dicho, de su propia formación en el galenismo y compaginarla con las experiencias que va adquiriendo en México.

La clave mayor que recomienda Cisneros, habida cuenta de la multitud de variables que se le presenta a quien venga a ejercer la medicina en un sitio tan particular es, descartada la efectividad real de las experiencias en su lugar de origen y las novedades a las que se ha de enfrentar es, sin lugar a duda la Astrología.

El motivo es fácilmente explicable. Según la mentalidad de la medicina de su tiempo y la ya aludida "cultura en torno a la medicina», la Astrología resulta ser el único elemento común en que él médico puede confiar a la hora de iniciar su tarea. Las influencias celestes son iguales en intensidad y también son fijas.

Por tanto, y a modo de conclusión, todas las variables que se puedan introducir, especialmente las relativas a los aspectos sanitarios de la Ciudad de México, tienen

${ }^{15}$ Cisneros, Diego, Sitio, naturaleza y propiedades de la Ciudad de México, México, Real Universidad de México, 1618. 
para Cisneros un elemento común en el que el médico puede confiar: la presencia de los astros y su influencia. Toda una garantía y un aval sobre la que incide fuertemente con el fin de encaminarse hacia la salud del enfermo. Tal era la visión de Cisneros ante las particularidades de una ciudad la de México. Gracias a él y a esta ciudad contamos, pues, con la visión que se tenía acerca de los aspectos sanitarios urbanos durante el siglo XVII. 


\section{Colecçãa \\ 2 Ciências e Culturas Caimbra 2006}

